\title{
The method of multivariate geological modeling and wells correlation of pashiysky horizon
}

\author{
M.G. Ayrapetyan \\ Postgraduate student, St. Petersburg mining University, St. Petersburg, Russia
}

\author{
A.A. Farukshin \\ Postgraduate student, St. Petersburg mining University, St. Petersburg, Russia \\ Y.V. Nefedov \\ PhD, Associate professor, St. Petersburg mining University, St. Petersburg, Russia
}

\begin{abstract}
This article describes the method of multivariate calculation of geological uncertainties and the first stage of the geological model construction - well correlation of the pashiysky horizon of Novosergievsky and Perevolotsky districts of the Orenburg region in the domestic tNavigator software product of RockFlowDynamics. This technique allows to construct geological models of the pashiysky horizon on variants P10 (optimistic), P50 (realistic), P90 (pessimistic), thereby to estimate risks and to carry out quality control of geological model. This method is used to construct structural maps of the roof and bottom of the pashiysky horizon.
\end{abstract}

\section{INTRODUCTION}

Against the background of the decrease in recoverable oil reserves of large deposits in the world and in Russia, the intensification of hydrocarbon production at current assets is a very urgent problem. One of the forced approaches to increase the production of hydrocarbons is the involvement in the development of small reserves and complex formations. A characteristic feature of field development in the oil and gas industry is the emphasis on the main object of development, while secondary layers may actually be no less profitable. Insufficient attention to secondary objects of development of oil and gas fields today is a challenge for oil and gas companies not only in Russia but also around the world.

One of such perspective layers is the pashiysky horizon of the Orenburg region. In the fields of the territory of Novosergievsky and Perevolotsky districts, the pashiysky horizon is a secondary potential object of development with a rather complex geological structure.

The problem of the object of research is the insufficiency of studying the formation, complex facies and tectonic structure, which leads to the impossibility of in-depth analysis of the filtration-capacitive properties of the horizon and its oil and gas potential. The interest to the object is caused by single wells producing oil from the pashiysky horizon, which indicates the confirmed oil and gas potential of the reservoir in the studied area. Thus, the identification of inhomogeneities and patterns of distribution of the filtration-capacitive properties of the pashiysky horizon will help to increase the understanding of the structure and geometry of the formation for further development.

This problem can be solved most rationally by methods of geological and hydrodynamic modeling on the basis of a detailed study of the regularities of the structure and properties of the formation. On the basis of data of geophysical researches of wells, their interpretation, core material, and also data on development it is possible to construct conceptual facies, structural and, as a result, geological model of a layer, as much as possible reflecting actual 
distribution of properties in a reservoir. And the first stage of the formation study is one of the tasks of this article - well correlation of the formation.

The second important task of the current article is the technique of multivariate modeling. The geologist's ideas about the geological structure of a deposit or formation are never exhaustive. Further decisions on field development depend on the reliability of the geological model. Due to the large number of uncertainties, the simulation will take place in a multivariate mode. In other words, each parameter or property of the formation and fluid will vary within certain boundaries already accepted by core studies and other data. At the final stage, this will determine the most likely model to make a decision and recommendations on drilling, geological and technical measures and production.

\section{WELL-TO-WELL CORRELATION}

In terms of petroleum Geology, the study area belongs to the East Orenburg oil and gas bearing area, which corresponds to the East Orenburg uplift in tectonic terms. The industrial oilbearing capacity of the area is associated with deposits of the pashiysky horizon, the Kolgan strata and the Tournai tier.

The Geology of Orenburg and the Orenburg region (Figure 1) includes sedimentary formations of the upper Proterozoic, Paleozoic and Mesozoic, which lie on igneous and metamorphic deposits of the Archean-early Proterozoic crystalline basement (Figure 2).

In the studied area, the main object of development is the Kolgan strata. However, a considerable number of vertical and directional wells opened pashiysky horizon (Figure 3)

Well-to-well correlation was carried out in the following stages (Figure 4, Figure 5):

1. The choice of the reference line, i.e., the reference horizon which can be traced in all the wells.

2. Selection of the reference section, that is, the most representative section, on which all reference layers are clearly well distinguished, sufficient power of the section is presented, a full complex of GIS is performed.

3. Comparison of well sections with reference section.

4. Well-to-well correlation according to different correlation schemes.

Well descriptions and core photos are attached to wells in the software simulator (Figure 6).

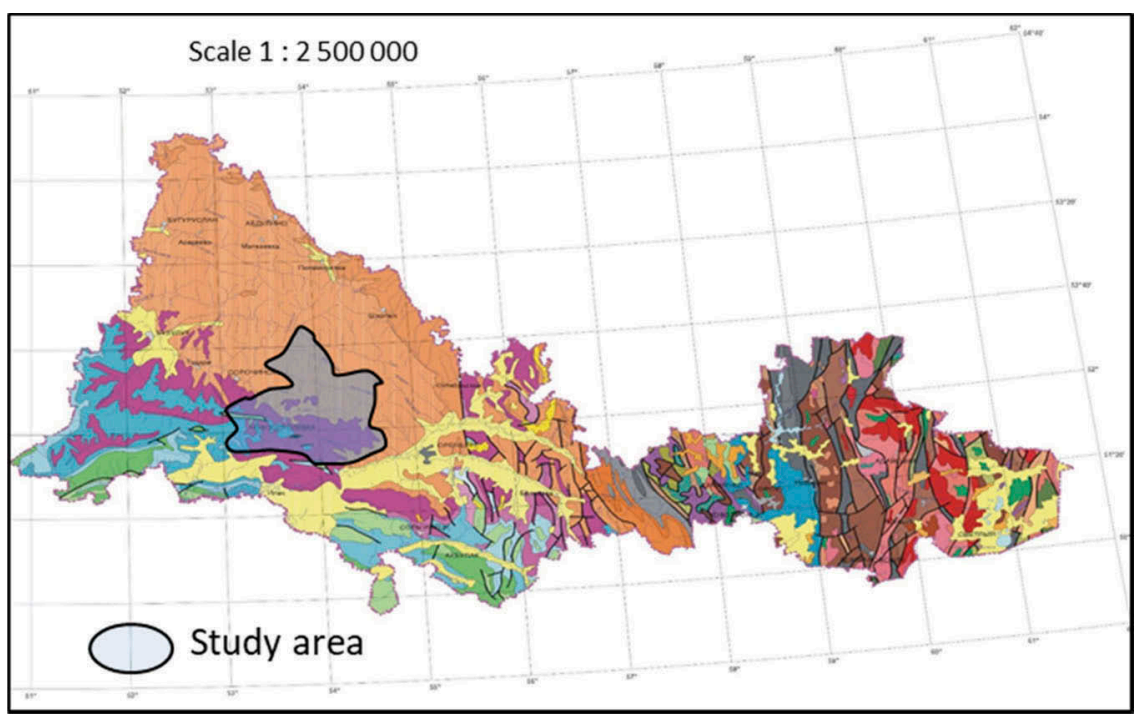

Figure 1. Map of pre-Quaternary formations of Orenburg region. 


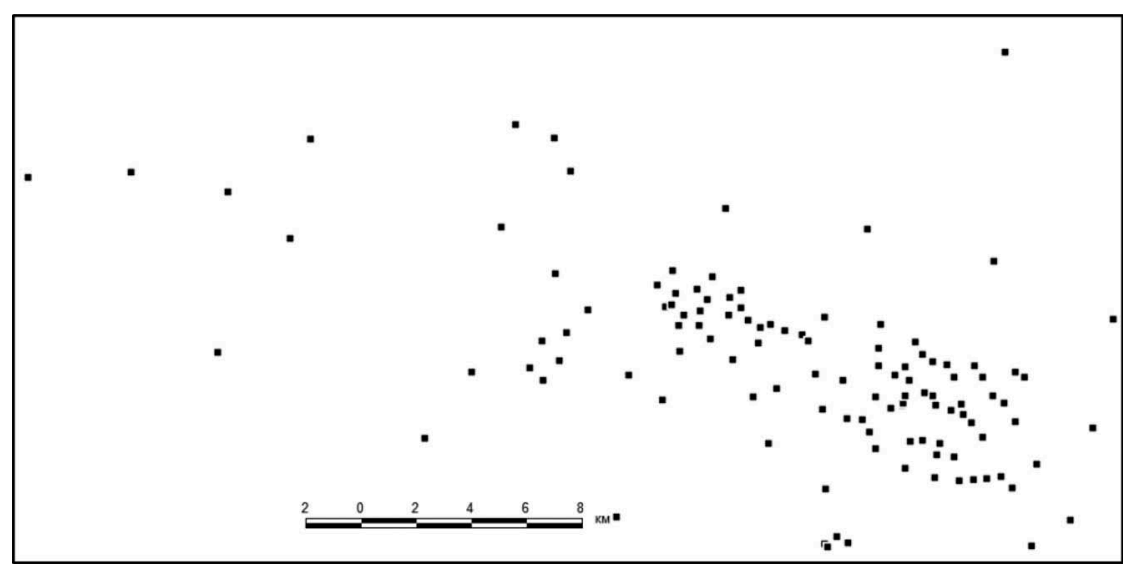

Figure 2. Wells, opening the main object of development in the study area.

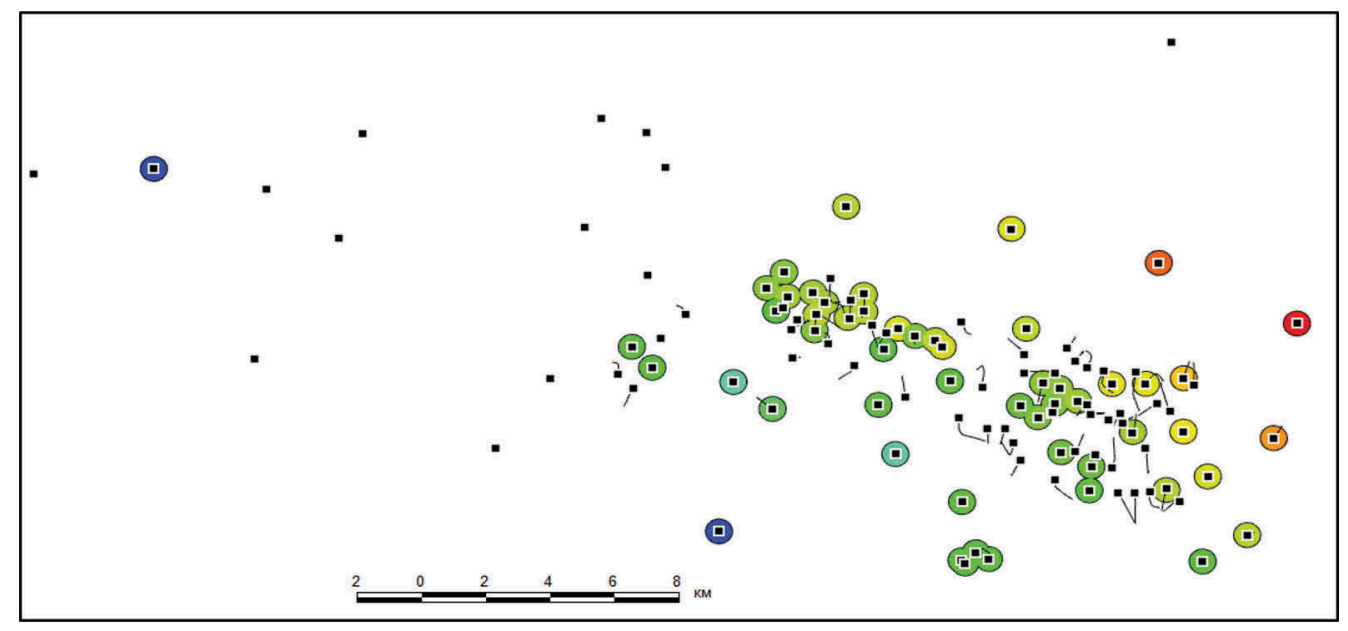

Figure 3. Wells that opened the roof of the pashiysky horizon.

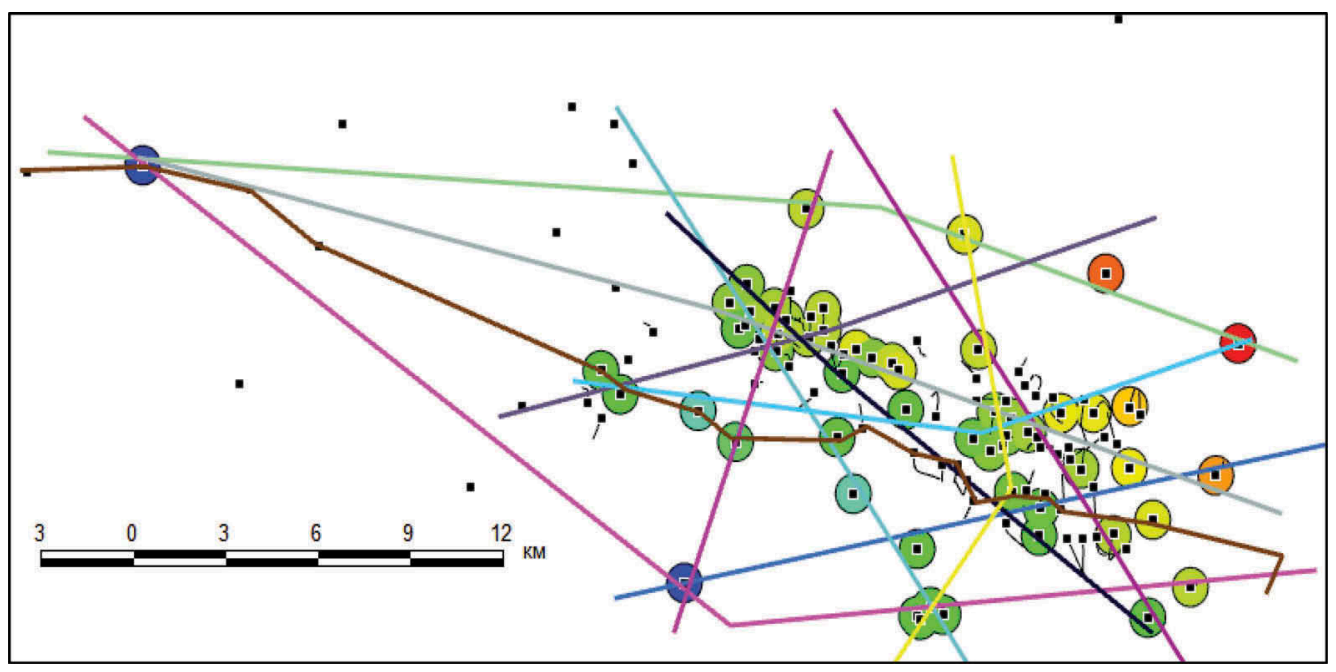

Figure 4. Correlation schemes. 


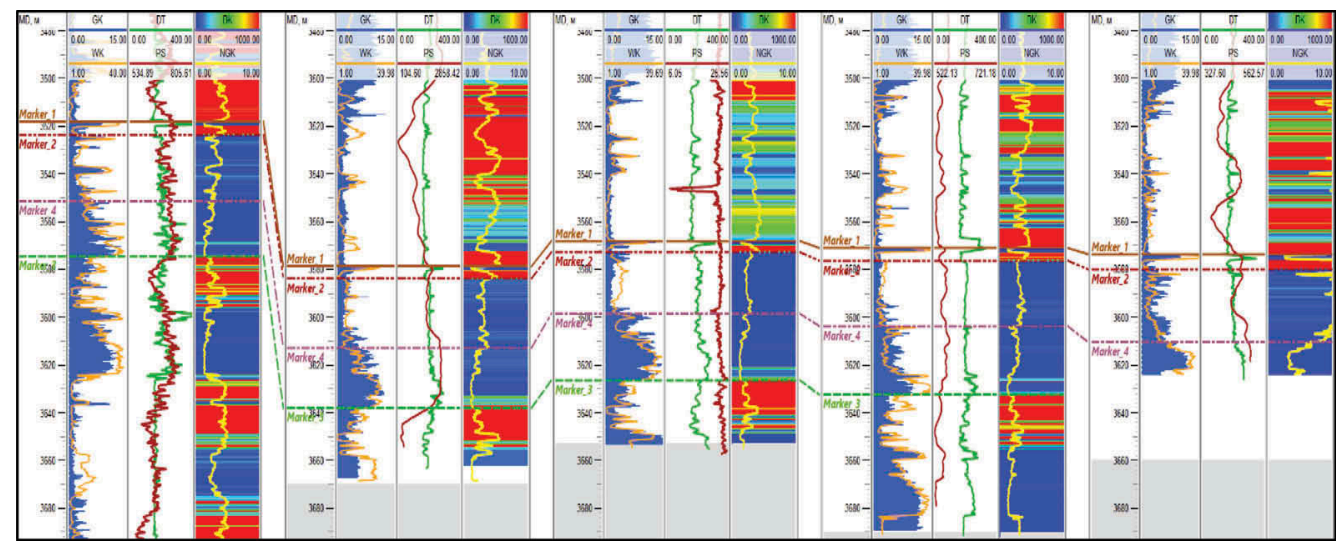

Figure 5. The correlation of the wells penetrated pashiysky horizon.

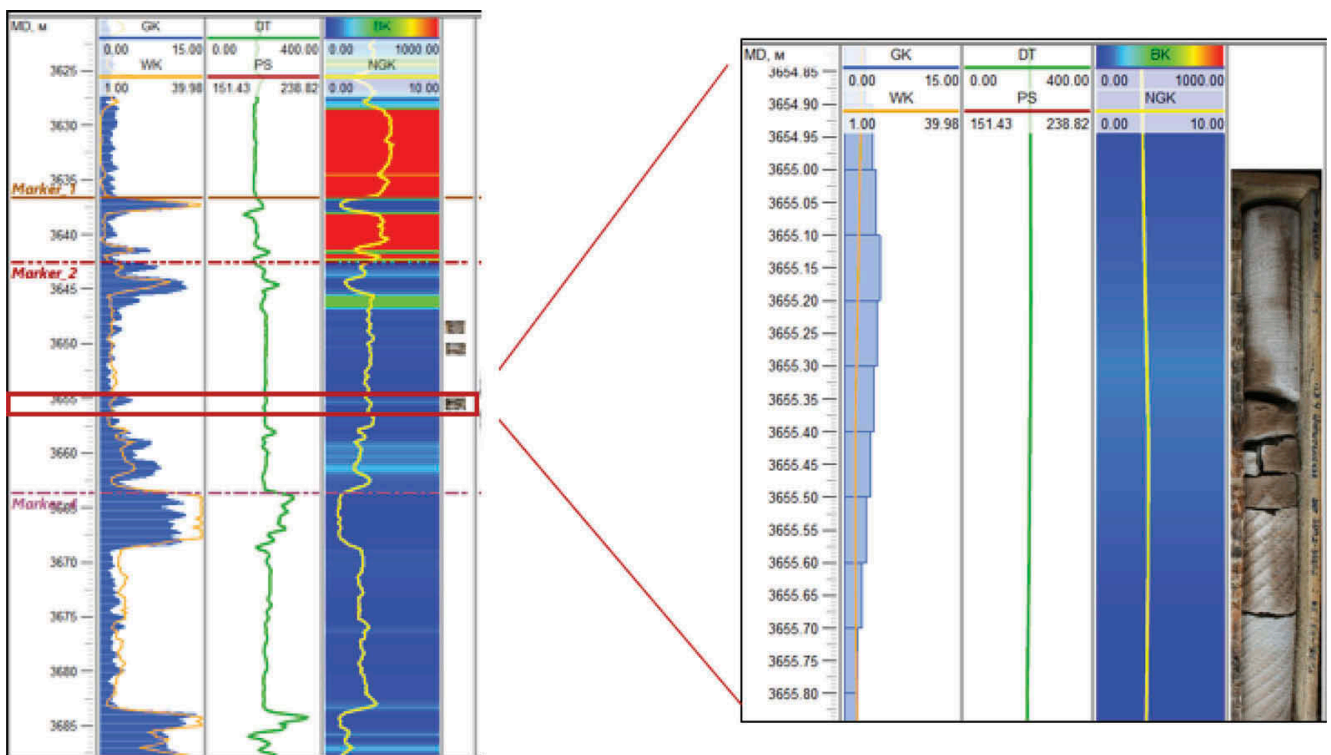

Figure 6. Snap photos and description of the core in the correlation scheme.

The peculiarity of the correlation of the pashiysky horizon was the inhomogeneous structure, which often causes difficulties when comparing well-logs curves. The lack of well data has become the reason for the interpolation of a formation over long distances. The pashiysky horizon is relatively constant in power in the area under study.

The pashiysky horizon is composed of fine - and fine-grained siltstone sandstones, with thin layers of siltstone and mudstone.

Reservoir rocks are sandstones light gray, light gray with a brownish tinge, quartz, porous, strong and medium strength, massive, lenticular-indistinctly layered, obliquely layered texture areas.

Dense clay sandstones, siltstones gray, dark gray, indistinctly layered, lenticular-layered and mudstones dark gray, thinly layered are common in the inefficient part of the formation.

The seal rock is a pack of mudstones of the roof part of the horizon, dark gray, dense, calcareous, with an uneven admixture of sand-silt material, thin-layered. 


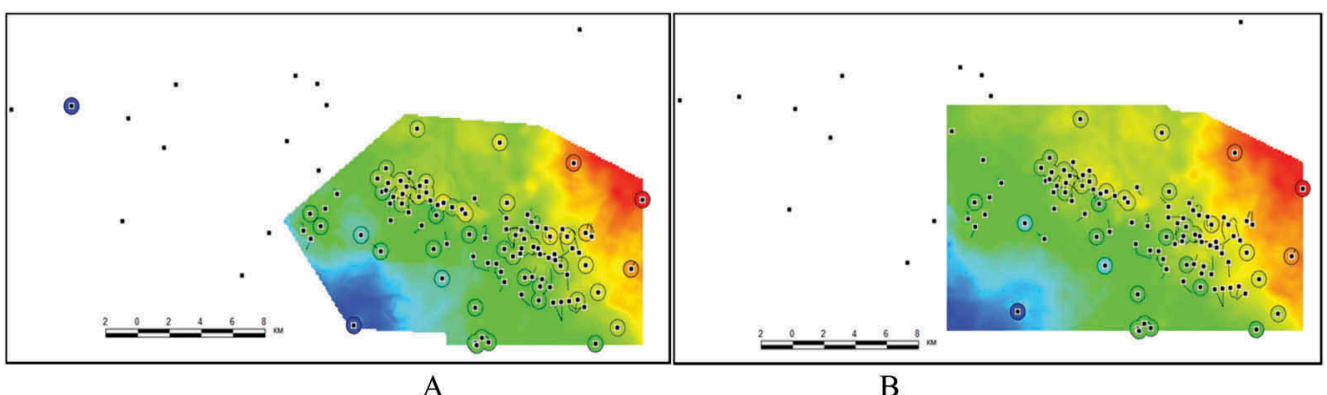

Figure 7. Map of the roof (A) and bottom (B) of the pashiysky horizon.

The deposits of the pashiysky horizon were formed in the conditions of the sea coast with mixed wave and river activity.

\section{MULTIVARIATE MODELING TECHNIQUE}

The technique of multivariate geological modeling is to vary the parameters and properties of the reservoir and fluid, in which there is no absolute value or there are doubts about their reliability. As a rule, dependencies and studies that are obtained in the process of processing the initial data, give a cloud of values and a significant spread with some trend.

As practice shows, deterministic methods of geological modeling give a figure of reserves, which can change during the development and updating of geological information.

The most important source of uncertainty in the construction of a geological model is the ambiguity of structural simulations.

Stages of multivariate modeling:

1. Estimation of the most probable depths of structural horizons in the inter-well space. The definition of the standard deviation of the depth.

2. Construction of structural horizons of the roof and the sole of the formation in the model.

3. Determination of lithological and genetic types of rocks and probability of distribution of sedimentary body morphology.

4. Filling of the structural framework with lithotypes based on borehole data, given forms of sedimentary body and probabilities of its size.

5. Reservoir filling with petrophysical properties based on probabilistic estimates of rock properties variability.

6. Calculation of hydrocarbon reserves by volumetric method for all possible variants of the geological model.

7. Choice of options P10 (optimistic), P50 (realistic), P90 (pessimistic)

Multivariate structural maps of the roof and sole of the formation were constructed on the basis of this technique and the correlation of the pashiysky horizon. Below are maps of the sole and roof of the pashiysky horizon according to the P50 variant (Figure 7).

\section{CONCLUSION}

As a result, the following conclusions were obtained:

- Correlation of the pashiysky horizon was carried out

- Snap photos and description of the core to the wells.

- Defines the uncertainty in the spacing layers

- The technique of multivariate geological modeling is proposed

- Maps of the roof and sole layers are constructed. 
It is important to use the multivariate approach in geological modeling, when a large amount of information is approximated.

The work showed an approach at the well correlation level. However, this approach is expected to be used at all stages of oil and gas field development.

\section{REFERENCES}

Ababkov K. V. (2010). Fundamentals of three-dimensional digital geological modeling. Ufa: "Oil and Gas business".

Bulgakov S. A. Investigation of layers of the pashiysky horizon by probabilistic-statistical Express method. Samara state technical University. "Oil and gas business" - Samara, 2011, 75 p.

Dudchenko, O.L., Fedorov, G.B., Andreev, A.A. (2018). Innovative method for the classification of coal slurries. "Ugol".

Gospodarikov, A.P., Zatsepin, M.A. (2019). Mathematical modeling of boundary problems in geomechanics. "Gornyi Zhurnal".

Gutman I. S., Balaban I. Yu., Isyangulova N. R., Potemkin G. N., et al. Modeling of complex oil and gas objects on the basis of detailed correlation of well sections in automatic and interactive modes// Neft. Gas.Innovations, No. 12, 2014. - Pp. 16-23.

Gutman I. S., Kuznetsova G. P. Classification of correlation of geological sections of wells in connection with the degree of study of oil and gas objects. Features of performance of comparison of geological sections of wells with use of the latest computer technologies. - Moscow: Gubkin Russian state University of oil and gas, 2006.

Zakrevsky K. E. (2009). Geological 3D modeling. Moscow: LLC CPI Mask.

Losheva Z. A., Magdeev M. sh., Agafonov S. G., Fedotov M. V., Magdeeva O. V. a New look at the geological structure of the pashiysky horizon (D3ps) of the Aznakaevskaya area of the Romashkinskoye oil field. Georesources. 2017. T.19. No. 1. Pp. 21-26.

Lyadsky P. V., Kvasnyuk L. N., Zhdanov A.V., Chechulina O. V. and others. State geological map of the Russian Federation. Scale 1:1,000,000 (third generation). A Series Of The Ural. Sheet M-40 (Orenburg) with valve M-41. Explanatory note. - SPb.: Map factory VSEGEI, 2013. 392 p. +1 incl.

Potemkin G. N. Features of geological structure and optimization of development of oil and gas potential of Devonian terrigenous deposits of the southern part of the Volga-Ural oil and gas province. Moscow: Gubkin Russian state University of oil and gas, 2016. - 137 c.

Prischepa, O., Nefedov, Y., Grokhotov, E. Geochemical and petrophysical studies of hydrocarbon potential of domanic shale formation (Timan-Pechora petroleum Province) EAGE/SPE Workshop on Shale Science 2019 - Shale Sciences: Theory and Practice DOI: 10.3997/2214-4609.201900475 ISBN: 978-946282281-8

Sinitsyn I. M., Sinitsyna G. I. State geological map of the Russian Federation. Scale 1: 200000. Series The Middle. Sheet O-40-XXXII (kuyeda). Explanatory note. - Moscow: Moscow branch of fsbi "VSEGEI", 2017. 81 PP.

Technical guide simulator "tnavigator". (2017). The Company "Rock Flow Dynamics". Moscow. 